\title{
Patient satisfaction with a novel one-step hydrogen peroxide solution
}

\author{
This article was published in the following Dove Press journal: \\ Clinical Ophthalmology \\ 6 October 2014 \\ Number of times this article has been viewed
}

\section{Jeffery Schafer \\ Robert Steffen \\ Marjorie J Rah}

Bausch \& Lomb Incorporated, Rochester, NY, USA
Correspondence: Marjorie J Rah

Bausch \& Lomb Incorporated, $1400 \mathrm{~N}$

Goodman St, Rochester, NY I4609, USA

Tel + I 5854 I3 6397

Email marjorie.rah@bausch.com
Purpose: We aimed to evaluate the product performance of a novel one-step hydrogen peroxide cleaning and disinfecting solution, PeroxiClear ("Test" solution), when used by habitual Clear Care users to bilaterally clean and disinfect their soft contact lenses, for approximately 2 weeks.

Methods: This was a 2-week, open-label, bilateral eye study designed to include subjects ranging in age from 18 to 55 years, inclusive. All subjects were habitual users of the Clear Care peroxide regimen for cleaning, disinfecting, and storage of their soft contact lenses, for at least 6 months prior to enrolling in the study. Subjects were examined at two study visits: a screening/dispensing visit and a 2 -week follow-up visit. The primary end point, patient preference for the Test solution, was evaluated with an online survey administered after 7 days of using the Test cleaning and disinfecting solution. Respondents could answer questions with neutral or nonneutral responses (better or worse). Statistical analyses were conducted to compare differences for nonneutral responses.

Results: Of the 299 eligible subjects enrolled, 297 completed the study, conducted at 21 sites by 21 investigators in the United States. A significantly higher proportion of nonneutral respondents reported the Test solution was better overall $(85.9 \%)$ than their habitual contact lens solution $(14.1 \%)(P<0.001)$. The proportion of subjects who preferred the Test solution over their habitual solution was significantly higher for each of the preference questions regarding comfort ( $85.4 \%$ vs $14.6 \%$ ), moistness ( $90.0 \%$ vs $10.0 \%$ ), cleanness $(91.6 \%$ vs $8.4 \%)$, and clarity of vision ( $85.8 \%$ vs $14.2 \%)$.

Conclusion: After 7 days of using the Test cleaning and disinfecting solution, survey results indicated high levels of patient satisfaction and preference over the habitual solution, particularly in the areas of comfort, moisture, and cleanness.

Keywords: disinfecting solution, contact lens care, contact lens comfort

\section{Introduction}

Current prescribing practices for lens care systems have shown an overwhelming trend towards multipurpose solutions (MPS), followed by one-step hydrogen peroxide $\left(\mathrm{H}_{2} \mathrm{O}_{2}\right)$ lens care systems. $\mathrm{H}_{2} \mathrm{O}_{2}$ lens care systems have been less frequently prescribed in recent years. In a study of patients ages 8 to 33 years old $(n=3,549)$, $78.1 \%$ versus $9.9 \%$ of soft contact lens wearers reported use of MPS and $\mathrm{H}_{2} \mathrm{O}_{2}$ lens care systems, respectively. ${ }^{1}$ In a UK survey evaluating prescribing practices from 1997 to 2007 , the prescription of $\mathrm{H}_{2} \mathrm{O}_{2}$ lens care systems decreased from $20 \%$ to $7 \%{ }^{2}$ The prescribing practice observed in France was somewhat greater, where 59\% of contact lens wearers in the general population used MPS and 35\% used oxidative products. ${ }^{3}$ According to a recent study, the use of $\mathrm{H}_{2} \mathrm{O}_{2}$ systems among US contact lens wearers is approximately $20 \%{ }^{4}$ 
$\mathrm{H}_{2} \mathrm{O}_{2}$ systems have typically been prescribed over MPS, to help improve comfort, and have been suggested as alternative cleaning systems for patients who experience ocular sensitivity to preservatives. ${ }^{3,5}$ For silicone hydrogel lens wearers, $\mathrm{H}_{2} \mathrm{O}_{2}$ systems have shown decreased corneal staining ${ }^{6-9}$ and have been thought to protect against corneal inflammatory responses. ${ }^{10} \mathrm{H}_{2} \mathrm{O}_{2}$ systems have also been shown to be effective antimicrobial agents. ${ }^{11-13}$ In rigorous in-vitro testing, 3\% $\mathrm{H}_{2} \mathrm{O}_{2}$-based systems had better microbicidal performance when compared with MPS solutions. ${ }^{12}$

Although prescribed less frequently than MPS, one-step and two-step $\mathrm{H}_{2} \mathrm{O}_{2}$ systems have shown good outcomes for subjective comfort, particularly in patients who have lens and solution incompatibility with marked corneal responses. ${ }^{14}$ In a study of 26 silicone hydrogel contact lens wearers, Keir et al compared a one-step $\mathrm{H}_{2} \mathrm{O}_{2}$ system with an MPS and found that subjects reported longer comfortable wearing times with the $\mathrm{H}_{2} \mathrm{O}_{2}$ system than the MPS. ${ }^{15}$ In addition, some researchers have proposed that preservative-free $\mathrm{H}_{2} \mathrm{O}_{2}$ lens care systems may provide better comfort to contact lens wearers who have experienced ocular discomfort or sensitivities with preserved MPSs ${ }^{5,11,16}$ or who have seasonal allergies. ${ }^{16}$ Although comfort was shown to improve with the use of an $\mathrm{H}_{2} \mathrm{O}_{2}$ system, there have also been reports of concomitant use of rewetting eye drops and some residual ocular symptoms, suggesting the need for further research on comfort measures. ${ }^{17}$

Although $\mathrm{H}_{2} \mathrm{O}_{2}$ systems have been prescribed as an option for increasing comfort, there are few published studies documenting the comfort-related outcomes with one-step $\mathrm{H}_{2} \mathrm{O}_{2}$ systems. The objective of this study was to evaluate the performance of a novel, one-step, $\mathrm{H}_{2} \mathrm{O}_{2}$ cleaning and disinfecting test solution (PeroxiClear solution; Bausch + Lomb, Rochester, NY, USA) ("Test" solution) when used by habitual Clear Care (CIBA Vision, Fort Worth TX, USA) users for bilateral cleaning and disinfecting of soft contact lenses for approximately 2 weeks.

\section{Methods}

This was a 2-week, open-label, single-arm, bilateral eye study designed to include subjects ranging in age from 18 to 55 years, inclusive. This study was conducted in accordance with Good Clinical Practice guidelines ${ }^{18}$ and the tenets outlined by the Declaration of Helsinki. The study received approval from the Southwest Independent Institutional Review Board, and all subjects provided informed consent. All subjects were habitual users of the Clear Care $\mathrm{H}_{2} \mathrm{O}_{2}$ regimen for cleaning, disinfecting, and storage of their soft contact lenses, for at least 6 months prior to enrolling in the study. In addition, subjects had to be adapted silicone hydrogel or hydrogel lens-wearers and had to agree to use the study solution and wear their lenses on a daily wear basis for the duration of the study; had to be myopic and require lens correction from -0.25 diopters to -6.00 diopters in both eyes; and had to have access to an internet connection and be able to send and receive email. Subjects who were aphakic, amblyopic, or who required monovision, multifocal, or toric contact lenses, or subjects currently wearing opaque cosmetic tint contact lenses were not eligible to participate.

Subjects were examined at two study visits: a screening/dispensing visit and a 2-week follow-up visit. All subjects were seen for a screening/dispensing visit, during which informed consent was obtained and eligibility was assessed. Subjects were asked to wear their habitual lenses to the screening/dispensing visit. At this visit, eligible subjects were dispensed a new pair of their habitual contact lenses and a study kit containing a bottle of the Test cleaning and disinfecting solution. The lenses were to be worn on a daily wear basis for 2 weeks, with no scheduled replacement, and the subjects were to use the assigned cleaning and disinfecting solution after removing the lenses each day for the 2-week duration of the study. Sensitive Eyes Plus Saline solution (Bausch + Lomb) was also dispensed to be used on an "as needed" basis. Subjects were instructed to use their habitual rewetting drops, if necessary. Subjects were also instructed that they must not use any other cleaning and disinfecting solution during the study and not use the cleaning and disinfecting solution directly in their eyes. After 7 days of using the Test cleaning and disinfecting solution, each subject completed an online survey. Patients also rated their experience with the Test solution on a scale of 0 to 100 at the time of the 2-week follow-up visit. A slit lamp evaluation was performed at both the screening/dispensing visit and the two-week follow-up visit.

\section{Test solution}

The Test solution was a one-step $\mathrm{H}_{2} \mathrm{O}_{2}$ lens care system for cleaning, protein removal, disinfecting, and storing of soft (hydrophilic) contact lenses, including silicone hydrogel contact lenses, and gas permeable lenses. The Test solution was a sterile buffered solution containing $3 \%$ stabilized $\mathrm{H}_{2} \mathrm{O}_{2}$, cleaners, and comfort agents that included a surfactant, a demulcent, and a humectant.

\section{Statistical analysis}

To test the proportion of subjects preferring the Test solution over their prestudy solution, a total of 272 respondents 
to the questionnaire were needed to provide $90 \%$ power to show that the proportion was greater than $50 \%$.

The primary outcome, patient preference for the Test solution, was evaluated by a patient-completed online survey administered after 7 days of using the Test solution. For the primary end point, two-sided, $95 \%$ confidence intervals (CIs) were constructed, using exact binomial tests, around the proportion of subjects preferring the Test solution over their habitual solution for each preference question. Change from baseline analyses were conducted where appropriate, using McNemar's tests for dichotomous end points and using paired $t$-tests for continuous end points.

\section{Results}

\section{Study population}

Of the 299 eligible subjects enrolled, 297 completed the study, conducted at 21 sites by 21 investigators in the United States (Figure 1). Two eligible subjects discontinued the study: one subject discontinued due to lack of motivation during the course of the study, and one subject due to hospitalization for a nonocular event. Of the 299 eligible subjects, 77 (25.8\%) were male and 222 $(74.2 \%)$ were female, with a mean (standard deviation [SD]) age of 31.6 (7.8) years (range: 18 to 54 years). The majority of subjects were White (262 [87.6\%]), 20 (6.7\%) were Asian, and ten $(3.3 \%)$ were African American. The majority of subjects (264 [88.3\%]) were not Hispanic and not Latino.

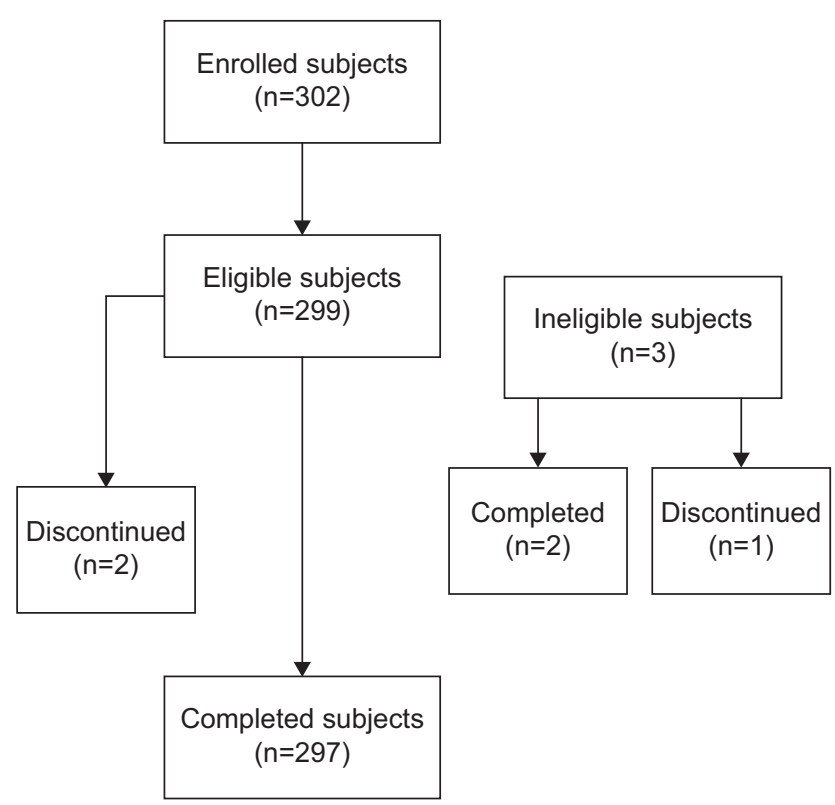

Figure I Patient disposition flow chart.

\section{Online survey after 7 days of use}

The questionnaire responses were grouped as better (includes "much better" and "somewhat better") or worse (includes "somewhat worse" and "much worse") than their habitual solution, or as neutral responses ("about the same as my usual solution"). Neutral responses were tallied but not included in the statistical comparisons as patient preference was necessary to test the primary statistical end point. A summary of the survey results is provided in Table 1.

For subjects with nonneutral responses, a significantly higher proportion of subjects indicated the Test solution was better overall (85.9\%) than their habitual contact lens solution $(14.1 \%)(P<0.001)$. Likewise, the proportion of subjects who preferred the Test solution over their habitual solution was significantly higher for each of the preference questions regarding overall comfort ( $85.4 \%$ vs $14.6 \%$ ), moistness $(90.0 \%$ vs $10.0 \%)$, cleanness ( $91.6 \%$ vs $8.4 \%)$, and clarity of vision ( $85.8 \%$ vs $14.2 \%)$. In addition, a significantly higher proportion of subjects $(>50 \%)(P<0.001)$ preferred the Test solution over their habitual solution because they experienced fewer symptoms with the Test solution compared with their habitual solution, including build up on lenses over the life of the lens ( $89.6 \%$ vs $10.4 \%)$, build up on lenses during the day $(88.3 \%$ vs $11.7 \%)$, lenses drying out over the course of the day ( $84.9 \%$ vs $15.1 \%)$, itchy eyes ( $84.9 \%$ vs $15.1 \%)$, dry eyes $(83.7 \%$ vs $16.3 \%)$, red eyes ( $83.7 \%$ vs $16.3 \%$ ), tired eyes $(81.7 \%$ vs $18.3 \%)$, blurry or hazy vision $(80.9 \%$ vs $19.1 \%)$, and irritation ( $77.5 \%$ vs $22.5 \%)$.

When asked whether they would choose the Test solution or their habitual solution if they were asked by their eye care practitioner, there was a 3:1 preference for the Test solution $(75.3 \%$ vs $24.7 \%)(P<0.001)$. A significantly higher proportion of subjects $(>50 \%)(P<0.001)$ gave a rating of agree than a rating of disagree for statements that the Test solution performed better than their habitual solution for statements, including the following statements: "gets my lenses really clean" ( $92.0 \%$ vs $8.0 \%)$, "keeps my lenses moist and comfortable all day long" ( $82.6 \%$ vs $17.4 \%)$, "prevents my vision from becoming blurry over the course of the day" $(82.6 \%$ vs $17.4 \%)$, "makes me feel that I am not wearing lenses" (78.7\% vs $21.3 \%$ ), and "the solution keeps my lenses comfortable no matter how long I wear them" (74.6\% vs $25.4 \%)$.

\section{Subjective ratings at screening/ dispensing and 2-week visit}

Subjects rated their subjective symptoms/complaints using a 0-100 scale, for each eye, at the screening/dispensing visit, based on their experience with their habitual lenses and lens 
Table I Subject preference survey: test solution versus habitual peroxide solution

\begin{tabular}{|c|c|c|c|c|}
\hline \multirow[t]{2}{*}{ Total responses $=287$} & \multirow{2}{*}{$\begin{array}{l}\text { Neutral } \\
\text { responses }^{\mathrm{a}} \\
\mathbf{N}(\%)\end{array}$} & \multicolumn{2}{|c|}{ Nonneutral response results ${ }^{b}$} & \multirow[t]{2}{*}{$P$-value ${ }^{c}$} \\
\hline & & Better & Worse & \\
\hline Overall, how does this solution compare & $81(28.2)$ & $177(85.9)$ & $29(14.1)$ & $<0.001$ \\
\hline \multicolumn{5}{|l|}{ to your usual contact lens solution } \\
\hline \multicolumn{5}{|l|}{ Comfort of contact lenses with this solution } \\
\hline \multicolumn{5}{|l|}{ compared to with your usual solution } \\
\hline Overall & $89(31.0)$ & $169(85.4)$ & $29(14.6)$ & $<0.001$ \\
\hline At the start of each day & $97(33.8)$ & $|7|(90.0)$ & $19(10.0)$ & $<0.001$ \\
\hline At the end of each day & $81(28.2)$ & $169(82.0)$ & $37(18.0)$ & $<0.001$ \\
\hline \multicolumn{5}{|l|}{ How moist did your contact lenses feel with this } \\
\hline \multicolumn{5}{|l|}{ solution compared to with your usual solution } \\
\hline Overall & $78(27.2)$ & $188(90.0)$ & $21(10.0)$ & $<0.001$ \\
\hline At the start of each day & $99(34.5)$ & $176(93.6)$ & $12(6.4)$ & $<0.001$ \\
\hline At the end of each day & $84(29.3)$ & $168(82.8)$ & $35(17.2)$ & $<0.001$ \\
\hline \multirow{2}{*}{\multicolumn{5}{|c|}{$\begin{array}{l}\text { How clean did your contact lenses feel with this } \\
\text { solution compared to with your usual solution }\end{array}$}} \\
\hline & \\
\hline Overall & $97(33.8)$ & I $74(9 \mid .6)$ & $16(8.4)$ & $<0.001$ \\
\hline At the start of each day & $95(33.1)$ & I8I (94.3) & II (5.7) & $<0.001$ \\
\hline At the end of each day & $113(39.4)$ & $153(87.9)$ & $21(12.1)$ & $<0.001$ \\
\hline \multirow{3}{*}{\multicolumn{5}{|c|}{$\begin{array}{l}\text { How clear was your vision with your contact lenses } \\
\text { using this solution compared to using your usual } \\
\text { solution }\end{array}$}} \\
\hline & & & & \\
\hline & & & & \\
\hline Overall & $132(46.0)$ & I $33(85.8)$ & $22(14.2)$ & $<0.001$ \\
\hline At the start of each day & $138(48.1)$ & I 34 (89.9) & $15(10.1)$ & $<0.001$ \\
\hline At the end of each day & $137(47.7)$ & $125(83.3)$ & $25(16.7)$ & $<0.001$ \\
\hline \multirow{2}{*}{\multicolumn{5}{|c|}{$\begin{array}{l}\text { Your experience with each of the following while } \\
\text { using this solution }\end{array}$}} \\
\hline & & & & \\
\hline Dry eyes & $72(25.1)$ & $180(83.7)$ & $35(16.3)$ & $<0.001$ \\
\hline Tired eyes & $145(50.5)$ & II $6(81.7)$ & $26(18.3)$ & $<0.001$ \\
\hline Irritation & $114(39.7)$ & I $34(77.5)$ & $39(22.5)$ & $<0.001$ \\
\hline Red eyes & $152(53.0)$ & II $3(83.7)$ & $22(16.3)$ & $<0.001$ \\
\hline Itchy eyes & $|4|(49.1)$ & $124(84.9)$ & $22(15.1)$ & $<0.001$ \\
\hline Blurry or hazy vision & $114(39.7)$ & $140(80.9)$ & $33(19.1)$ & $<0.001$ \\
\hline Lenses dry out over the course of the day & $69(24.0)$ & $185(84.9)$ & $33(15.1)$ & $<0.001$ \\
\hline Build up on lenses during the day & $99(34.5)$ & $166(88.3)$ & $22(11.7)$ & $<0.001$ \\
\hline Build up on lenses over the life of the lens & $105(36.5)$ & $163(89.6)$ & $19(10.4)$ & $<0.001$ \\
\hline Need to use eye drops to relieve discomfort & $132(46.0)$ & I 34 (86.5) & $21(13.5)$ & $<0.001$ \\
\hline
\end{tabular}

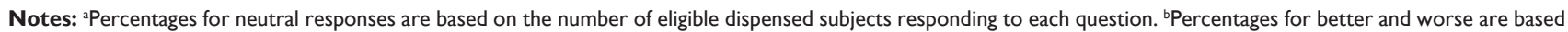
on the number of eligible dispensed subjects responding to each question that were nonneutral responses. ${ }^{c} P$-values are from exact binomial tests comparing the proportion of nonneutral subjects agreeing with the statement, to 0.5 .

care system; and at the 2-week follow-up visit, based on their experience with the dispensed lenses worn during the study while using the Test solution. Zero represented the least favorable rating and 100 represented the most favorable rating. At the 2-week follow up, all Test solution scores were favorable for symptoms/complaints, with mean scores ranging from 79.1 to 92.1 . When compared against the ratings from the screening/ dispensing visit, representing the habitual solution, significant changes $(P \leq 0.03)$ from baseline in favor of the Test solution were noted for the following: burning/stinging upon insertion (mean increase of 3.5), comfort upon insertion (mean increase of 3.9), comfort at end of day (mean increase of 7.7), dryness (mean increase of 7.5), itchiness (mean increase of 2.2), redness (mean increase of 2.3), vision (mean increase of 1.5), and lens cleanness upon removal (mean increase of 5.5).

There was a significant decrease in rewetting drop usage after subjects were switched from their habitual solution to the Test solution. At baseline $31.9 \%$ of subjects used rewetting drops compared with just $24.1 \%$ after using the Test solution $(P=0.003)$.

\section{Safety}

There were no eyes with slit lamp findings greater than grade 2 at either the screening/dispensing visit or the 2 -week 
follow-up visit. There were no adverse events reported, and there were no eyes with slit lamp findings or symptoms that required medical treatment during the course of the study.

\section{Discussion}

This study evaluated the performance of a novel one-step $\mathrm{H}_{2} \mathrm{O}_{2}$ cleaning and disinfecting solution (Test), when used by habitual users of another $\mathrm{H}_{2} \mathrm{O}_{2}$ solution to bilaterally clean and disinfect their soft contact lenses for approximately 2 weeks. In the present study, survey respondents reported high levels of satisfaction and preference for the Test solution compared with the habitual solution. Compared with baseline, there were statistically significant changes favoring the Test solution in ratings of burning/ stinging upon insertion, comfort upon insertion, comfort at end of day, dryness, itchiness, redness, vision, and lens cleanness upon removal. In addition, patients reported significantly less use of rewetting drops when compared with baseline.

$\mathrm{H}_{2} \mathrm{O}_{2}$ systems have been shown to provide increased comfort compared with MPS solutions and have been prescribed for patients with reactions to preservatives. . $^{511,16}$ To our knowledge, this is the first reporting of outcomes with this novel peroxide solution, thus study comparison was limited by lack of published outcomes. The present study compared the novel Test solution with the habitual peroxide lens care system; however, previous studies have shown improved comfort with $\mathrm{H}_{2} \mathrm{O}_{2}$ over MPS,, 16 while others found no significant differences. ${ }^{15}$

Study outcomes from the present study showed significant improvements in overall comfort and multiple comfortrelated areas when compared with the habitual system. Although some respondents offered neutral responses, the vast majority of subjects reporting nonneutral responses reported improved (better) comfort with the novel $\mathrm{H}_{2} \mathrm{O}_{2}$ Test solution than with their habitual system. In particular, $\geq 90 \%$ of nonneutral respondents reported better comfort due to lenses being moist, clean, and clear at the start of the day. These improvements were also reflected in the subjective scores for burning/stinging upon insertion and comfort upon insertion, which favored the Test solution over the habitual solution. Results also indicated ongoing comfort throughout the day as a high majority of respondents also agreed the Test solution kept their lenses moist and comfortable all day long and comfortable no matter how long lenses were worn. The subjective ratings with the greatest increase in comfort from baseline were those for comfort at the end of the day, dryness, and lens cleanness upon removal.
In the present study, there was a significant decrease in rewetting drop use after subjects were switched from their habitual peroxide solution to the Test solution. Although increased comfort has been reported over MPS with one-step $\mathrm{H}_{2} \mathrm{O}_{2}$ systems, the concomitant use of eye drops has also been reported. In the US and Germany, $31 \%$ and $27 \%$ of patients, respectively, reported using eye drops in conjunction with their $\mathrm{H}_{2} \mathrm{O}_{2}$ solution at least once per week. The decrease in rewetting drop use with the Test solution in the present study may be attributed to the three hygroscopic (water loving) comfort agents in the solution. The presence of these agents was detected in a laboratory study analyzing unworn silicone hydrogel (senofilcon A) lenses stored for 12 hours in the Test solution and then analyzed for uptake. ${ }^{19}$ The results indicated there was uptake of the surfactant, demulcent, and humectant during the solution exposure. The presence of these comfort agents may have contributed to improved comfort and less rewetting drop use when compared with the habitual peroxide system.

Comfort-related outcomes provide valuable information about the patient experience with contact lens products and can aid in understanding causes of lens dissatisfaction and discontinuation..$^{20,21}$ In a large survey of contact lens wearers with lapsed or discontinued use, the primary reasons for discontinuation were discomfort, dryness, and redness. ${ }^{21}$ Furthermore, about $23 \%$ of those surveyed had dropped out of contact lens use permanently. Similarly, another study found a $24 \%$ rate of permanent discontinuation of contact lens wear. ${ }^{20}$ Providing patients with a comfortable contact lens experience is imperative for retaining these patients. $\mathrm{A} \mathrm{H}_{2} \mathrm{O}_{2}$ system may be a good option for patients with symptoms related to solution sensitivities, allergies, and end of day dryness. Comfort is multifactorial, and patients should be assessed comprehensively for factors that may be causing ocular discomfort.

The open-label, nonrandomized study design could be viewed as a limitation, although the real-world setting speaks to the practical application of comfort-related outcomes with this novel $\mathrm{H}_{2} \mathrm{O}_{2}$ lens care system for which there are limited reports. This study evaluated patient comfort and preference after 7 days, but future studies could assess comfort after a longer duration of use. However, the time frame used in the study also allowed for recall of the subject's experience with habitual solutions. The age of the patients' habitual lenses at baseline was not evaluated; therefore, the newness of the lenses dispensed at the onset of the study may also be viewed as a limitation. Future studies could include a washout period between uses of the solutions tested. 
Use of the online survey minimized the potential for bias that could be introduced by on-site questions or instructions about the survey and ensured a standardized questionnaire across sites. Future studies could evaluate outcomes of this novel $\mathrm{H}_{2} \mathrm{O}_{2}$ lens care system in different study populations, such as symptomatic and asymptomatic patients or possibly in patients with allergies. Other studies could also compare subjective outcomes with other active or habitual comparators, such as two-step $\mathrm{H}_{2} \mathrm{O}_{2}$ systems or MPS. The continued use of rewetting drops and contact lens-related symptoms with use of MPS and $\mathrm{H}_{2} \mathrm{O}_{2}$ products supports the need for further comfort-related research, particularly in patients with sensitivities to MPS products.

\section{Conclusion}

After 7 days of using the Test solution, patients reported high levels of patient satisfaction and preference over the habitual solution, particularly in the areas of comfort, moisture, and cleanness. There were statistically significant changes from baseline in favor of the Test solution, for burning/stinging upon insertion, comfort upon insertion, comfort at end of day, dryness, itchiness, redness, vision, and lens cleanness upon removal. The novel one-step $\mathrm{H}_{2} \mathrm{O}_{2}$ solution used in this study provided patients with improved comfort outcomes compared with their habitual solution.

\section{Disclosure}

All authors were employees of Bausch \& Lomb Incorporated at the time of this work. The authors declare no other conflicts of interest in this work.

\section{References}

1. Lam DY, Kinoshita BT, Jansen ME, et al; CLAY Study Group. Contact lens assessment in youth: methods and baseline findings. Optom Vis Sci. 2011;88(6):708-715.

2. Efron N, Morgan PB. Soft contact lens care regimens in the UK. Cont Lens Anterior Eye. 2008;31(6):283-284.

3. Dutot M, Paillet H, Chaumeil C, Warnet JM, Rat P. Severe ocular infections with contact lens: role of multipurpose solutions. Eye (Lond). 2009;23(2):470-476.

4. Nichols JJ. Growth in some specialty areas and consensus on lens discomfort highlighted an otherwise stable year. Contact Lens Spectrum. 2014;29:22-28.

\section{Clinical Ophthalmology}

\section{Publish your work in this journal}

Clinical Ophthalmology is an international, peer-reviewed journal covering all subspecialties within ophthalmology. Key topics include: Optometry; Visual science; Pharmacology and drug therapy in eye diseases; Basic Sciences; Primary and Secondary eye care; Patient Safety and Quality of Care Improvements. This journal is indexed on
5. Dillehay SM, McCarter HE; AOSept Clear Care Study Group. A comparison of multi-purpose systems. A study compares patient dryness and discomfort symptoms found with MPS and a one-bottle peroxide system. Contact Lens Spectrum [serial on the Internet]. 2002 Apr [cited 2014 Aug 14]:[about 6 p.]. http://www.clspectrum.com/ articleviewer.aspx?articleID=12132. Accessed August 14, 2014.

6. Carnt N, Jalbert I, Stretton S, Naduvilath T, Papas E. Solution toxicity in soft contact lens daily wear is associated with corneal inflammation. Optom Vis Sci. 2007;84(4):309-315.

7. Andrasko G, Ryen K. Corneal staining and comfort observed with traditional and silicone hydrogel lenses and multipurpose solution combinations. Optometry. 2008;79(8):444-454.

8. Amos C. A clinical comparison of two soft lens care systems used with silicone hydrogel contact lenses. Optician. 2004;227(5933):16-20.

9. Begley CG, Edrington TB, Chalmers RL. Effect of lens care systems on corneal fluorescein staining and subjective comfort in hydrogel lens wearers. Int Contact Lens Clin. 1994;24(1-2):7-13.

10. Carnt N, Keay L, Naduvilath T, et al. Risk factors associated with corneal inflammation in soft contact lens daily wear [abstract]. Invest Ophthalmol Vis Sci. 2007;48:4326.

11. Thakrar V. Soft contact lens solutions: 2008 update. Eye Care Review. 2008;2(2):21-23.

12. Hildebrandt C, Wagner D, Kohlmann T, Kramer A. In-vitro analysis of the microbicidal activity of 6 contact lens care solutions. BMC Infect Dis. 2012;12:241.

13. Pinna A, Usai D, Zanetti S, Thomas PA, Kaliamurthy J. Susceptibility of various corneal fungal isolates and Pseudomonas aeruginosa to contact lens disinfecting solutions. J Infect Dev Ctries. 2013;7(3):261-268.

14. Papas EB, Carnt N, Willcox MD, Holden BA. Complications associated with care product use during silicone daily wear of hydrogel contact lens. Eye Contact Lens. 2007;33(6 Pt 2):392-393; discussion 399-400.

15. Keir N, Woods CA, Dumbleton K, Jones L. Clinical performance of different care systems with silicone hydrogel contact lenses. Contact Lens Anterior Eye. 2010;33(4):189-195.

16. Dillehay S, Chalmers RL. Relief of symptoms with clear care in contact lens wearers who formerly used multipurpose lens care system. In: American Academy of Optometry; 2004; Tampa, Florida.

17. Rah MJ, Mack CJ. Issues and symptoms experienced during soft contact lens wear while using hydrogen peroxide solutions. Optom Vis Sci. 2012;89:E-abstract 125993.

18. Good Clinical Practices Guidelines [webpage on the Internet]. Silver Spring: US Food and Drug Administration. Available from: http://www. fda.gov/aboutfda/centersoffices/officeofmedicalproductsandtobacco/ cder/ucm090259.htm. Accessed September 5, 2014.

19. Groemminger L, Liu XM, Millard K, Hoteling A. Triple moisture system for hydrogen peroxide solution. Poster presented at: Global Specialty Lens Symposium; January 23-26; 2014; Las Vegas, NV.

20. Richdale K, Sinnott LT, Skadahl E, Nichols JJ. Frequency of and factors associated with contact lens dissatisfaction and discontinuation. Cornea. 2007;26(2):168-174.

21. Dumbleton K, Woods CA, Jones LW, Fonn D. The impact of contemporary contact lenses on contact lens discontinuation. Eye Contact Lens. 2013;39(1):93-99.

PubMed Central and CAS, and is the official journal of The Society of Clinical Ophthalmology (SCO). The manuscript management system is completely online and includes a very quick and fair peer-review system, which is all easy to use. Visit http://www.dovepress.com/ testimonials.php to read real quotes from published authors. 